\title{
Struggling to Address the 'Big and Burning' Questions: The Opportunities and Perils of (Austrian) Political Science Going Mainstream
}

\author{
Reinhard Heinisch \\ University of Salzburg, Department of Political Science and Sociology, Austria \\ reinhard.c.heinisch@sbg.ac.at
}

\begin{abstract}
This essay raises the question of whether mainstream political science fails to address adequately the important questions about the state of democracy that are dominating the current public discourse. Increasingly common research practices in mainstream political science focus on technical questions and puzzle-solving while incentivizing conventional approaches and narrow risk-averse scholarship. This threatens political science's ability to contribute meaningfully to the public discourse. Under these circumstances, the Austrian branch of the discipline is joining mainstream international political science in a quest for greater relevance after decades of marginalization. The article traces the evolution of postwar international and Austrian political science, suggesting that the current focus on puzzle-solving is a reaction to previously dominant paradigms in the discipline that made grand claims on the basis of few data. The essay also shows that the delayed establishment of Austrian political science as an academic discipline and its long disconnect from international developments in the field long undermined its recognition. Now that it is becoming more mainstream and international, there are unprecedented opportunities for greater prestige but also new perils to be avoided.
\end{abstract}

\section{Keywords}

relevance, political science, mainstream, puzzle-solving, Austria

The author has declared that no competing interests exist. 


\section{Introduction}

Why does political science seem rather irrelevant in the public discourse on the crisis of democracy and the rise of populism? This essay asks whether political science is failing to make a meaningful contribution to the public debate precisely at the time when the discipline has been shaking off its reputation, especially in Austria, as a countercultural project. Relevance is understood here not in terms of the share of articles by Austrians in flagship journals - I take this to be an indicator of the growing mainstreaming of our field-but in terms of political science's ability to affect the public discourse on key political questions. So this article addresses societal relevance in terms of the identity of the profession and the value attributed to it by society: Do national legislators and policymakers seek out political scientists' expertise? Do media outlets discuss important insights of political science scholarship? Do school curricula draw on our field for lessons learned? The answer is: very rarely.

Even those of us with more frequent media appearances will have to admit that such commentary is less about their scholarship and more about promoting the academic discipline to taxpayers who ultimately foot the bill but have not the faintest idea of what we do. My central point is twofold: On the one hand, political science in Austria is coming into its own as an empirical social science at last and thus claiming a position it already holds in North America and other Western European countries. I regard this as a positive development overall. Consequently, our discipline may derive additional prestige and wider consideration. On the other hand, this development has done little thus far to increase the relevance of our field in the eyes of the public, especially among those concerned about the current apparent crisis of democratic legitimacy and representation. I would also suggest that this is partly because of how we practice our discipline.

\section{How Did We Get Here?}

The I960s and I970s cast a long shadow in political science, not only in Austria. In some sense, the field is still reacting to this period, which continues to divide scholars along epistemological and generational lines. In the decades following the Second World War, political science was far more paradigmatic in orientation and confident in addressing the big questions plaguing society (on this point, see also Ennser-Jedenastik et al. in this issue). The young discipline was sure it could tackle questions such as how to transition to democracy, how to fix underdevelopment, how to liberalize society and contain communism, and how to engender a civic culture anywhere from Mexico to Germany. Initially, this self-confidence was buoyed by the sudden availability of mainframe computers in major universities in the US, where the GI bill had given large numbers of war veterans access to higher education.

These new universities and their more traditional academic competitors, which suddenly felt the need to upgrade their own programs, required new faculty members. Thus, many Central European and German scholars fleeing persecution and war entered American academe. These European transplants-people such as Paul Lazarsfeld, Oscar Morgenstern, Heinz Eulau, Hans Morgenthau, Karl Deutsch, and Ern(e)st Haaspossessed not only a clear normative agenda in the form of liberal democracy at all costs but were also steeped in the Hegelian and Weberian traditions and passed both legacies on to their American students. This meant that attitudes and values were the ultimate independent variable explaining political outcomes. The new dominance of behaviorist political science was in part a consequence of the fact that old-style institutionalism, comparing constitutions and formal rules, had proved inadequate for explaining the rise of early twentiethcentury totalitarianism.

Confident in Weberian notions that values and ideas precede material reality, a new postwar generation of scholars threw themselves into answering the big and burning questions. Seemingly value-neutral, the new paradigm presumed American democracy and civil society to be the gold standard. It is thus not surprising that David Apter argued that "good things (referring to capitalism and democracy) go to together." All one had to do was to break down parochial habits and traditional structures while letting loose enough "modernizers" (people converted to modern values through targeted programs) to engender change. Within the community of modernization theorists and comparatists, Almond and Verba's magnum opus on civil culture is probably the culmination of this endeavor and has become a classic both for its significant achievements and spectacular failures.

A closely related paradigm was classical systems theory, in which discreet structures and corresponding functions governed all social systems. In response to input and output functions, these systems were constantly said to recalibrate themselves in an effort to maintain stability-heuristically, it was the dawn of cybernetics and its imagery pervaded concepts in the social sciences. It is striking from today's perspective that both behaviorist and systems theories were strangely devoid of politics or anything "political." Political outcomes were foreshadowed by tallying certain

\footnotetext{
I In a lecture given at Virginia Tech in 1986 referring to his book The Politics of Modernization (1965).
} 
attitudes and subtracting others, usually represented by arrow diagrams and feedback loops. Institutions were little more than empty boxes. Only in certain niches and subfields were other émigrés from Europe, such as Leo Strauss at the University of Chicago and the progressive thinker Theodore Lowi, continuing to promote political science beyond the behaviorist paradigm.

As the postwar wave of democratization gave way to authoritarianism in much of the then decolonized developing world, the hypotheses underpinning modernization theory and systems theory could no longer be supported. Consequently, the discipline shifted. As Kuhn (1962) had suggested, a new generation of social scientists brought about a paradigmatic revolution. It was none other than the young Samuel Huntington who shattered the Parsonian myth of the nature of self-sustaining systems in his $\mathrm{PhD}$ thesis, published as Political Order in Changing Societies (1968). He showed that economic development is uneven and tends to engender instability and counter-reactions. The destruction of the established social fabric does not automatically give way to modernization, but in fact often brings chaos and radicalization.

The latter part of the I960s and I970s saw the rise of another strand of German sociology, which descended from the left-wing Hegelian tradition as represented foremost by Karl Marx. That approach took the material and thus economic conditions as constituting an inevitable prerequisite for all social interaction. Politics and political institutions were thus inescapably part of the superstructure that rested upon the all-important economic base. Drawing on Marxism, Andre Gunder Frank (1966)-another German sociologist transplanted to US academe-and others argued in development politics that the world was inevitably divided into a core and periphery because capitalism required the developed nations to derive the necessary surplus value from the underdeveloped periphery. Otherwise, Marx had postulated, the rate of profit was bound to fall. The clash between the haves and have-nots was a dialectically pre-programmed historical necessity, they argued. Once again, politics and institutions, supposedly the core concern of political scientists, did not seem to matter, but were determined by the mode of production. Crucially, however, Marxist and other radical scholars preferred to discuss the big questions, just as their logical positivist forebears had done.

We can draw two key inferences from this initial discussion. First, the evolution of political science and its dominant paradigms was closely bound up with specific sociological and contextual factors connected to US postwar society. Second, both positivist and post-positivist political science sought to address major questions and global problems, albeit with scant data. The gap between actual observations and general conclusions was often filled by normative assumptions and conjecture. This pattern was not lost on a newer generation of mostly American scholars who eventually developed a preference for explaining much narrower phenomena but with greater certainty. In some sense the preoccupation with mid-level rather than grand theories, the preference for specific puzzles rather than broad questions, and the fixation with copious data and narrowly constructed causal mechanisms rather than provocative theorizing owes much to this intergenerational dynamic. That these issues are also surfacing in the debate over the relevance of Austrian political science has much to do with the discipline's delayed establishment here and its prolonged disconnect from the international mainstream. How this occurred will be examined in the next two sections.

\section{The Delayed Evolution of Political Science in Austria}

In few places were post-positivist ideas more influential than in Austrian political science, which came into its own institutionally in the I970s (see the overview of the history of political science in Austria from its state-building origins to pre-WWII anti-empiricism to the postwar search for an orientation in Decker et al in this issue). Shaped by both American and German influences as well as a peculiar local hostility to the social sciences, the field arrived late on the scene. Austria's great reluctance to embrace logical-positivism and mainstream empiricism remains astounding in light of the enormous contribution Austrian and Central European intellectuals had made to the field. ${ }^{2}$ What could have been a triumphant intellectual homecoming from an Austrian perspective and, as such, a late vindication for the many social scientists forced into exile, turned out to be quite a different affair. For one, in a country still steeped in anti-Semitism, no real effort was made after the war to recall the social scientists forced into exile. It was not only that many of the scholars were Jewish, but also that the new social sciences as a whole had been regarded suspiciously as "Jewish" disciplines and were as such unwelcome (Taschwer 2015). Moreover, in the clientelist world of Austrian Proporz politics and consensus democracy, which extended far into academia, unpredictable outside parties were not invited to prevent upsetting the delicately balanced arrangements. Lastly, the quasi-hegemonic field of jurisprudence was eager

2 This included Hans Kelsen's school of legal positivism, the Austrian school of economics, pioneering efforts in game and decision theory as well as the Vienna Circle's development of the scientific method, not to mention Joseph Schumpeter's work on democracy along with important applied and empirical research conducted by Paul F. Lazarsfeld, Maria Jahoda, and Hans Zeisel. 
to preserve its monopoly of access to the state and its intuitions. Thus, the generally conservative orientation of Austrian universities initially prevented political science from establishing itself as a modern social science inside the academy (cf. Karlhofer/Plasser 2012). Having developed under the auspices of the department of philosophy (University of Vienna) and law schools (University of Salzburg), the discipline in Austria exhibited a strong bias in favor of legal, philosophical, system-theoretical, and historical approaches along with a decidedly normative orientation. When political science finally became fully established in the I970s during the reformist Kreisky-Era, it largely embraced a non-mainstream orientation and was widely regarded as a Revolutionswissenschaft (Pelinka 1996, 4).

The influence from Germany manifested itself not only in ideas and publications but also in personnel. ${ }^{3}$ The growing intellectual presence of the critical and dialectical approaches in the new social sciences added to a chorus of criticism of mainstream political science and its methodology. It is thus rather ironic that generations of political science students were obligated by the curriculum to take courses in statistics and research methods, despite otherwise studying in an environment in which the whole notion of positivist social science was largely rejected outright or where these methods were hardly ever applied (cf. Kothe, et al. I988). Institutionally, this meant that mainstream social science was practiced outside the major university departments in Vienna at institutes such as the Institute of Advanced Studies.

On the other end of the political spectrum, traditional normative political philosophers derided the lack of prescriptive quality in the sense that a value-free science was essentially without value if it could not tell right from wrong. In fact, Sickinger (2004) concluded that the main achievement of the Austrian Society of Political Science (ÖGPW) was the establishment of the discipline as a "critical social science." For many normative scholars, especially those working in the Marxist tradition, positivist research (taken to imply quantitative methods) was inexorably bound up with the American capitalist project and seen as antithetical to genuine emancipation.

Nonetheless, the new generation of critical and postpositivist scholars also saw themselves as tackling the big questions in Austria and elsewhere. In fact, it does not get much bigger than Wallerstein's (1974) world systems theory, an approach widely taught in Austrian political science long after its I970s international heyday. Macro-level explanations were central to understanding social reality. In this regard, this generation was scarcely

3 In fact, by the mid-I99os, about a third of professors had previously held appointments in Germany. distinguished from the logical positivists that had come before.

\section{The Austrian Disconnect}

Austrian political science's delayed emergence and its peculiar connections to certain strands in German academe (the Positivismusstreit and the intellectual dominance of the Frankfurt School) insulated it from changes sweeping the field in other countries, especially the US. There, the totalism and historicism of the Marxist critique ultimately proved a poor match for the fundamentally empiricist orientation of American political science. As with the behaviorist paradigm, empiricism served once more as a corrective to the sweeping theoretical claims about emancipation and the need for a revolution. Starting in the late 1970s, another generation of American political scientists saw the tenets of dependency as wholly deterministic and little more than a quasi-religion dear to their "I960s professors" that was irreconcilable with emerging markets and the failures of self-reliance strategies from North Korea to Tanzania. Meanwhile, other scholars like Ronald Inglehart (1977, 1990) had begun reviving parts of the classical behaviorist framework without reifying it through all-encompassing claims.

Coming out of American graduate schools in the I980s, political scientists were searching for a new approach to studying politics. A major source of frustration was that Marxism, like behavioralism before it, had little regard for political science's stated core concern: politics itself, the state, and its organization. The deterministic prism of the critical framework combined with a multitude of ad-hoc exceptions to explain away empirical anomalies (especially in macrolevel theories like New Dependency Theory and World Systems Theory) was conceptually and practically dissatisfying.

The pioneering work of a new generation of scholars in the I980s - Peter Evans, Atul Kohli, Theda Skocpol James March and Johan Olsen - brought about a major turn in the field that largely skipped Austria, at least initially. With their seminal article "Bringing the State Back In", Evans and Skocpol (1985) realigned political science to focus, once again, on politics and its institutional underpinnings. The institutionalist revolution was influenced by work outside the mainstream such as Barrington Moore's (1966) Sociological Origins of Dictatorship and Democracy as well as by an eclectic mélange ranging from Weber to Huntington and Almond to Habermas. In a way, the field had come full circle; the regimes and political institutions themselves mattered once again. They were viewed as creating their own logic, defining spaces of meaning and providing specific 
incentives and disincentives for action. Institutionalism also had the great advantage that it lent itself to gametheoretical modeling on one end of the spectrum as well as quantitative analysis and qualitative scholarship on the other (Peters 1999). Nonetheless, its impact in Austria at the time remained limited and was not felt until much later. Austrian political scientists continued to perceive their American colleagues through the prism of the I950s paradigms of modernization and systems theory.

\section{Toward Puzzle-Solving}

Reacting to the shortcomings of previous paradigms, mainstream political science shifted the focus to more concrete questions for which sufficient data could be gathered. Mid-level theories and hypotheses that could more easily be falsified became the norm. Scholarship became more cautious and wanted to avoid overinterpreting empirical observations and making all too sweeping generalizations. Research proceeded from a single and clearly stated research question, required a solid, specified research design, and needed to present clearly testable prepositions based a theoretically persuasive causal mechanism. Mainstream political science embraced puzzle-solving, which itself betrays an inherent skepticism toward big but fuzzy questions in which too many variables impinge on too few cases. This is not to say that that scholars are not trying to understand fundamental questions of human behavior, but that preference is given to explaining rather less but that with greater certainty.

As puzzle-solving approaches became established in the top publications, it grew increasingly difficult to publish looser, more theoretical works. Thus, explicitly normative and non-mainstream work found it harder to enter the kinds of key journals that decide careers. In some cases, different epistemic communities were able to maintain their own separate academic ecosystems if they possessed international networks of a critical mass, could show tangible connections to British or American universities, and/or included internationally renowned scholars. The Vienna School in Critical Discourse Analysis comes to mind as an example of an alternative with this type of pedigree. As a result of this trend, political science in Austria and elsewhere has undergone a significant degree of compartmentalization, which, in a small country, means that different epistemologies had to learn to live side by side.

\section{Consequences of the Quest for "Excellence"}

In many Western and Northern European countries, the establishment of epistemologically based performance criteria and the definition of official standards has shattered the comfortable notion that all departments and all manners of scholarship were roughly equally valid and thus equally good. When infusions of federal money poured into German universities so that some institutions became officially designated "excellent," a new standard of relevance was set. In the remaining seemingly "non-excellent" departments, the professoriate suddenly found itself relegated to the second tier and in some sense rendered less (academically) relevant. Along with their allies in the traditional media, they struck back, accusing the toptier researchers of being interested more in impact metrics and publications in obscure journals than in contributing to national debates about the big questions. The implication is that democracies are falling apart at the seams, but all that political science can offer is more equations. Critics of the emerging new mainstream are calling this development the assault of economization on the Humboldtian university tradition of erudite and holistic reflection.

Thus, we have arrived at competing narratives about relevance and irrelevance both within and outside the community of political science. In Britain, traditionally at the forefront of metrics on excellence, the quest for relevance has since resulted in a greater emphasis on "impact"; but in terms of impact on political decision making and societal change, not in the traditional academic sense. While this raises all sorts of questions about selection bias and public meddling in research, the new trend is arguably a reflection of concerns about the nature of mainstream social science as becoming too self-absorbed and narrow without sufficiently considering broader societal questions.

In Austria, neither a government-sanctioned epistemological definition of excellence in social science nor any generally approved measures of realworld impact have been introduced to date. Even the way the Austrian statistics office measures scientific publications in our field can only be described as bizarre. The very categories provided by the automated "system of research documentation" (FODOK) are a hodgepodge of thematic preferences and subfields most likely representing individual predilections of formerly important members of the professoriate. Perhaps the relative irrelevance accorded to political science by political decision-makers is an advantage in the sense that politicians simply do not care one way or another about what we do and how we do it. Thus, the live-andlet-live approach, an atmosphere of benign mutual neglect, appears to be persisting for the time being.

Nonetheless, positivist political science is slowly advancing in Austria as well4. The application of

4 Cf. the table on the Proportion of all SSCI publications in political 
international standards for promotions and grant acquisitions, which research agencies and university administrators cannot ignore, create effective mechanisms that inevitably give preference to certain types of research over others. It has become harder for national communities to insulate themselves from international trends, especially those coming from places that dominate the leading journals and claim the lion's share of international research budgets. Local strategies to avoid direct competition with mainstream social science, by exploiting otherwise untapped issue areas or cooperating across the discipline with epistemologically and theoretically more amenable fields such as cultural studies, can only go so far. $\mathrm{PhD}$ graduates in search of careers soon realize their competitive disadvantage without a proper grounding in what is internationally considered the state of the art in research design and methodology. As the turn to positivist political science becomes more established in Austrian scholarship, its international impact and visibility will increase. This, in turn, may boost its relevance-or will it?

\section{Reformers Vindicated?}

Those troubled by the history of Austrian political science scholarship should feel vindicated that change has arrived. Has political science not all too often substituted ideology for analysis by cherry-picking evidence and avoided international exposure by working in a comfortable language shared only by like-minded Germans? Yet, there seems little cause for celebration. We are undoubtedly confronted these days by "big and burning questions", not only in Austria but also across the Western world and beyond. The rise of authoritarian populism around the globe has spawned an unprecedented wave of research on this issue. Scores of books are published every year and now even an entire journal devoted to populism is being launched. Yet, for all the attention this issue is receiving, the definitive answers and possible solutions to the problems posed by populism-if we could only agree on their precise nature-have been few. Veteran populism researcher Cas Mudde (20I6), a mainstream Dutch empiricist, recently called for a fourth wave of scholarship on populism, contending that work this far has proved less than satisfactory. The new wave would transcend the familiar boundaries and established conventions of the field by pairing scholarship in political science with the insights of psychology, communication, and in-depth qualitative analysis.
The ascendency of positivist political science scholarship bears a risk, one that critical theorists have long known but mainstream scholars often refuse to acknowledge. Any scientific community is a human project with a characteristic sociology. While the scientific method may be inter-subjectively applicable and thus objective in this sense, science as a community enterprise is not. The rigors of career promotion and publications carry with them the tendency to avoid risk, ask safe questions, work within established conventions, plow through the familiar data, and solve a specific puzzle here or there. The idea that we will have all the answers oncewe have solved enough puzzles is an illusion because the questions we ask and the approaches we select are not determined by science alone, but by criteria bound up in our human society. Populism research is a case in point. For many years, it was conducted using a binary theoretical framework (parties were classified as either populist or non-populist) largely because this pattern fit Western European party systems. It was of little importance that scholars working on populism in Eastern and Southern Europe found the dominant paradigm wholly inadequate because they mattered less in the international power structure and because they-often writing in their native languages - had a limited audience. The dominance of certain approaches and research traditions, which all "happen" to hail from the economically and technologically most advanced countries, has objective reasons (access to information, adequate resources to finance research, strong institutions, etc.) but also subjective and normative ones.

In fact, what counts as a "big" or "burning" question is socially and normatively defined. Science unfolds in human communities and thus a sociology of science applies here as well. In science, as everywhere, "stardom" and influence are not solely functions of quality. Otherwise, why would so many use communitybased tools such as social media to tweet and discuss their latest achievements? In the end, we all need to be ahead of the pack in our search for a job and a paycheck.

Cultural myopia and the sociological limitations inherent in our scientific communities are not the only dangers threatening the relevance of our work in terms of correctly identifying the important questions and developing answers. The logic of publishing at all cost in a small group of select journals entails two great risks. Any conceptual risk-taking or deviations from the norm usually increase the likelihood of rejection, a reality that junior scholars in precarious working arrangements cannot ignore. 


\section{What Should Be Done?}

I am fully aware that that my concerns expressed here can be misconstrued as a call for more "bad" science with less rigor and clarity. To this, I would reply by suggesting that more data and more sophisticated methods may not provide satisfactory answers because of the limitations inherent in data collection and the open-ended nature of the problem. What we also need is reflection and the integration of different disciplinary perspectives (see also Decker et al on this point); not as a substitute for good data, but as a means of interpreting and relaying data to an audience for whom data are often inscrutable. Puzzle-solving per se is not the problem but not connecting the puzzles solved to broader questions for fear of insufficient rigor leaves the findings necessarily small in light of big problems. In some ways, we have to learn to do both.

Western democracies are being swept by rapidly unfolding, mutually influential changes, which are subject to overlapping push and pull factors. Even teasing out the role of culture versus economics has proved elusive-with numerous studies championing one or the other as the major independent variablebecause these two concepts cannot always be meaningfully separated. The motives of blue-collar workers may be both economic and identity-based, given that socioeconomic roles create cultural identities. Equally hard to measure is the role of a person's expectations relative to life experience. People may not be fully conscious of their own expectations, nor are those expectations constant over time. Still, these issues may be salient when evaluating political performance. Even more concrete aspects of expectations are hard to assess. While there is some good evidence of the measurable effect of pessimism and the experience of economic crisis on an individual's perception of institutional legitimacy and social trust, this is only one of many relevant variables and its impact appears small. Why does populism succeed in so many countries that seem ostensibly the wealthiest, the most economically successful, and even least corrupt in comparison to their counterparts? (I am thinking here of Switzerland, the Scandinavian countries, Northern Italy, and recessionera Poland.) How do we meaningfully compare people's expectations in different countries relative to how they weigh the political offers presented by change agents?

Comparative surveys run into problems when translating complex culturally and linguistically defined terms. (For example, do we translate "Do you consider yourself an average American?" with "Sehen sie sich als durchschnittlicher Deutscher?" or "...typischer Deutscher"?)

5 This is a real example from a comparative survey that is currently being developed.
Definitional and conceptual problems abound in most of the large internationally available data sets. Even scholars who ponder these issues, question the underlying constructs, and trace the origins of the variable's conceptualization have little choice but to live with the limitations of what is available.

At the very least, the use of large-scale surveys ensures randomization, replicability, and some measure of generalizability. The increasingly popular experimental and quasi -experimental designs may hold the key to addressing deeper questions rooted in individual personality and psyche. But here we encounter limits of comparability and generalizability.

This raises the question of how to measure the extent to which people form deep narratives about themselves and the political system in which they operate. In her in-depth interviews with scores of Trump and Tea Party voters, sociologist Arlie Hochschield (2016) shows how people end up feeling like "strangers in their own land" and, as such, not only assess politics very differently but become energized enough to vote for a radical populist after years of passivity. However, studies like these are often too culturally specific and inconsistent to allow for broader comparisons.

In short, the demand side of the issue alone presents numerous variables. Then, there is the supply side. How do successful populist parties find the right mixture of moderate and radical grassroots activists for a given political system? How do such parties retain cohesion and effectively centralize power and decision-making given their ever more varied organizational forms?

As a consequence of these numerous specialized considerations, the articles published along these lines are often narrowly focused and of little interest to even the audience of peers. Even if claims that 90 percent of social science articles remain uncited and most are never even looked at are exaggerated, ${ }^{6}$ we all know that many publications are read-if at all-by only a handful of specialists. This specialization means that scholarship is becoming more self-referential and impenetrable for policymakers, the media, and of course the public at large.

To tackle the problem, political science needs to transcend methodological orthodoxy and work more closely with other disciplines, such as psychology, communications, and cultural studies - despite the risk inherent in mixing research designs. There needs to be space in our field for unconventional approaches rooted in the insights of neighboring disciplines. There must be also room for theory development and informed conjecture, especially where data are poor and empirical analysis has proven unsatisfactory. It is especially important that innovative theorizing is not solely the

6 See Dahlia Remler 
prerogative of the senior professoriate, whose career trajectory may allow them to break with the rules of the system; instead, they should be encouraging younger scholars to contribute innovative insights.

There needs to be also space to translate findings into the public discourse. A question such as whether traditional catch-all parties ('Volksparteien') are finished deserves a meaningful answer not in the sense of a 95-percent significance level but of an informed analysis by scholars familiar with the arguments and literature.

The public expects answers from us. If political science does not deliver, other fields or other epistemic communities will gladly take our place in offering proposals and explanations. If democracy is in crisis and we are unable to provide a coherent set of answers on how to move forward, the relevance of our research will be increasingly called into question. Why does this matter? Because those judging the relevance and value of political science scholarship do pay our bills. In the end, we cannot count on benign neglect. We must account for our contribution to society.

\section{Conclusion}

For as long as political science was perceived as largely a countercultural phenomenon heavily suffused with ideology, policymakers and the public did not consider the discipline particularly relevant. Establishments simply do not take revolutionaries seriously as partners. Now that political science in Austria is becoming more mainstream, receiving all the top European Union grants and regularly being featured in the best journals in the field, its newly acquired scientific caché provides an opportunity for addressing important societal questions in an impactful manner. However, the mainstreaming of Austrian political science also means that it, too, is affected by trends in our field that may spoil our opportunity to tackle the big concerns. The frequent focus on technical questions and limited problems, often described in a language impenetrable to all but a few specialists in a subfield, makes such research uninteresting to larger audiences, even in the field itself. While some of this is unavoidable and even necessary, the field cannot sustain itself unless it is capable of more. These problems are further exacerbated by research practices that incentivize conventionality, risk -aversion, and narrowness over originality, ingenuity, and creativity. This is not a plea to return to more ideology or fuzzy arguments, but there must be more room for innovative theorizing and experimentation as well as for transcending disciplinary boundaries and methodological conventions. To be relevant to people concerned about the big and burning questions, political science must contribute innovative solutions to our primary political problems. If we are unable to address them, others will gladly step in to fill the gap.

\section{References}

Almond, Gabriel and Sidney Verba (1963), The Civic Culture: Political Attitudes and Democracy in Five Nations, Princeton: New University Press.

Ennser-Jedenastik, Laurenz/Thomas M. Meyer/Markus Wagner (2018), The Relevance of Empirical Political Science in Austria: Ask Important Questions, Study Them Rigorously, and Let People Know, in: ÖZP Austrian Journal of Political Science, Vol. 47(3), 33-42.

Evans, Peter and Theda Skocpol (1985), Bringing the State Back In, Cambridge: Cambridge University Press.

Frank, Andre Gunder (1966), The Development of Underdevelopment, in: Monthly Review, Vol. I8(4), I7-3I

Hochschild, Arlie Russell (2016), Strangers in Their Own Land: Anger and Mourning on the American Right, New York: New Press Publishers.

Huntington, Samuel (1968), Political Order in Changing Societies, New Haven: Yale University Press.

Inglehart, Ronald (1977), The Silent Revolution, Princeton: Princeton University Press.

Inglehart, Ronald (1990), Culture Shift, Princeton: Princeton University Press.

Karlhofer, Ferdinand/Fritz Plasser (2012), Die Innsbrucker Politikwissenschaft: Konsolidierung und Profilbildung, in: Österreichische Zeitschrift für Politikwissenschaft (ÖZP), Vol. 4I(I), 95-II 2.

Kothe, Michael, Andreas Mayr, Joself Melchior, Martin Mitterhauser and Hannes Roither (1989), "Student(in) und Methode. Zur politikwissenschaftlichen Ausbildungsistuation in Österreich.",in:Österreichische Zeitschrift für Politikwissenschaft, Vol. I8(I), 6I-76.

Kuhn, Thomas (1962), The Structure of Scientific Revolutions, University of Chicago Press.

Moore, Barrington (1966). Sociological Origins of Dictatorship and Democracy. Boston: Beacon Press.

Mudde, Cas (2016), The Study of Populist Radical Right Parties: Towards a Fourth Wave. C-Rex Working paper series No. I (on-line edition), Internet: https:// www.sv.uio.no/c-rex/english/publications/c-rexworking-paper-series/Cas\%2oMudde:\%20The\%20 Study\%2Oof\%2oPopulist\%2oRadical\%2oRight\%2O Parties.pdf (accessed: 20/10/2018)

Pelinka, Anton (1996), Politikwissenschaft in Österreich, in: Swiss Political Science Review, Vol. 2(4), I-70.

Peters, Guy (1999), Institutional Theory in Political Science - The 'New Institutionalism', London: Pinter.

Remler, Dahlia "Are 90\% of academic papers really never cited? Reviewing the literature on academic citations." In LSE-Impact Blog on-line (20/10/2018) http:// 
blogs.lse.ac.uk/impactofsocialsciences/2014/04/23/ academic-papers-citation-rates-remler/

Sickinger, Hubert (2004), Die Entwicklung der österreichischen Politikwissenschaft, in: Helmut Kramer (ed.): Demokratie und Kritik - 40 Jahre Politikwissenschaft in Österreich, Frankfurt am Main, 27-69.

Taschwer, Klaus (2015), Hochburg des Antisemitismus: Der Niedergang der Universität Wien in der ersten Hälfte des 20. Jahrhunderts, Wien: Czernin.

Wallerstein, Immanuel (1974), The Modern WorldSystem: Capitalist Agriculture and the Origins of the European World-Economy in the Sixteenth Century, New York: Academic Press.

\section{Author}

Reinhard Heinisch is Professor of Comparative Austrian Politics in at the University of Salzburg, Austria where he also chairs the Department of Political Science. His main research interests are comparative populism, Euroscepticism, and democracy. He is the author of numerous publications, including most recently Understanding Populist Organization: The West European Radical Right (Palgrave 2016/ co-edited) and Political Populism: A Handbook (Nomos 2017/co-edited). His most recent journal article is "Populism and ethno-territorial politics in European multi-level systems" Comparative European Politics (2018). Currently, he serves as a lead partner in a new EU-funded Horizon 2020 project devoted to studying populism and response strategies. 
